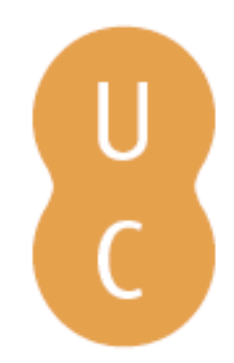

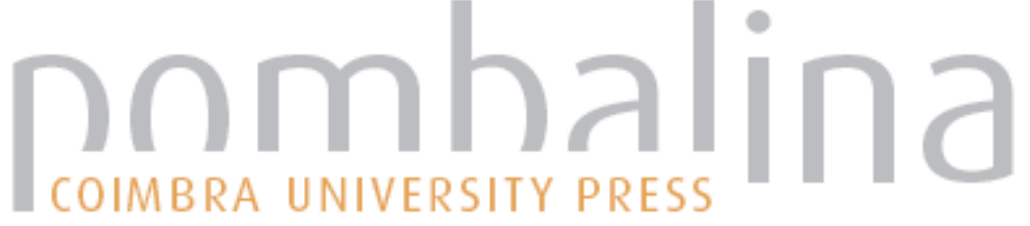

\section{Decapitação e exibição do inimigo como discurso e exercício de poder no império neoassírio}

\author{
Autor(es): $\quad$ Monte, Marcel L. Paiva do \\ Publicado por: Imprensa da Universidade de Coimbra \\ URL \\ persistente: URI:http://hdl.handle.net/10316.2/45217 \\ DOI: $\quad$ DOl:https://doi.org/10.14195/978-989-26-1626-1_8 \\ Accessed : $\quad$ 26-Apr-2023 01:30:40
}

A navegação consulta e descarregamento dos títulos inseridos nas Bibliotecas Digitais UC Digitalis, UC Pombalina e UC Impactum, pressupõem a aceitação plena e sem reservas dos Termos e Condições de Uso destas Bibliotecas Digitais, disponíveis em https://digitalis.uc.pt/pt-pt/termos.

Conforme exposto nos referidos Termos e Condições de Uso, o descarregamento de títulos de acesso restrito requer uma licença válida de autorização devendo o utilizador aceder ao(s) documento(s) a partir de um endereço de IP da instituição detentora da supramencionada licença.

Ao utilizador é apenas permitido o descarregamento para uso pessoal, pelo que o emprego do(s) título(s) descarregado(s) para outro fim, designadamente comercial, carece de autorização do respetivo autor ou editor da obra.

Na medida em que todas as obras da UC Digitalis se encontram protegidas pelo Código do Direito de Autor e Direitos Conexos e demais legislação aplicável, toda a cópia, parcial ou total, deste documento, nos casos em que é legalmente admitida, deverá conter ou fazer-se acompanhar por este aviso.

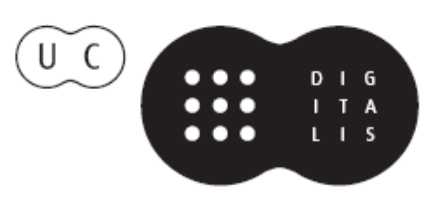




\section{Arqueologias de Império}

\section{Delfim Leão, José Augusto Ramos, Nuno Simões Rodrigues (coords.)}

IMPRENSA DA UNIVERSIDADE DE COIMBRA 


\title{
DECAPITAÇÃO E EXIBIÇÃO DO INIMIGO COMO DISCURSO E EXERCÍCIO DE PODER NO IMPÉRIO NEOASSÍRIO ${ }^{1}$ \\ (Decapitation and exhibition of the enemy as discourse and exercise of power in the Neo-Assyrian empire)
}

\author{
Marcel L. Paiva do Monte \\ (marcelpetroski@gmail.com; ORCID: 0000-0002-2811-3459) \\ CHAM - Centro de Humanidades, NOVA FCSH/UAc
}

\begin{abstract}
Resumo - Em contextos de violência, militar ou venatória, a decapitação é um ato de inusitada atrocidade cujo propósito é sobretudo simbólico e semiótico. Ato de propaganda, elemento de rituais ou signo de triunfo, a apropriação da cabeça de um inimigo - componente visível fundamental da identidade e do ser - é uma sinédoque poderosa que manifesta a sua derrota e a ruína de tudo o que representa para o vitorioso. Neste trabalho, são expostas reflexões sobre o papel da caput hostis como instrumento discursivo do poder político na Assíria do I milénio a.C., estabelecendo diferentes significados produzidos pelas suas modalidades de expressão visual e textual.
\end{abstract}

Palavras-chave: Decapitação; Guerra; Assíria; Assurbanípal; Teumman.

Aвstract - In military or venatory contexts of violence, decapitation is a startling atrocity with a mostly symbolic and semiotic purpose. An act of propaganda, element of rituals or sign of triumph, the appropriation of an enemy's severed head - a crucial visible component identity and self - acts as a powerful synecdoche that manifests its physical defeat and the ruin of everything he stands for to the victor. In this work are presented a few reflections concerning the role of the caput hostis as discoursive instrument of political power in Assyria during the 1st millennium BCE, establishing some of the different meanings produced by several modes of textual and visual expressions.

KeYwords: Decapitation; Warfare; Assyria; Ashurbanipal; Teumman.

A decapitação de um inimigo e a exibição da sua cabeça como troféu tem um significado autoevidente: a derrota e humilhação de um homem e a suprema

${ }^{1}$ Abreviaturas usadas: CAH III-2: 1991 - The Cambridge Ancient History, Vol. 3, part 2: The Assyrian and Babylonian Empires and other States of the Near East, from the Eighth to the Sixth Centuries B.C.; OIP 2 - Luckenbill, D. D. 1924. The Annals of Sennacherib (Oriental Institute Publications 2); RIMA 2 - Grayson, A. K. 1991. Assyrian Rulers of the Early First Millennium BC I (1114-859 BC); RINAP 3/1 - Grayson, A. Kirk, Novotny, Jamie (eds.) 2012. The Royal Inscriptions of Sennacherib, King of Assyria (704-681 BC), Part 1; SAA IV - Queries to the Sungod. Divination and Politics in Sargonid Assyria (State Archives of Assyria IV); SAA IX - Assyrian Prophecies (State Archives of Assyria IX); SAA XI - Imperial Administrative Records, Part II: Provincial and Military Administration (State Archives of Assyria XI); ARAB - Luckenbill, D. D. 1968. Ancient Records of Assyria and Babylonia. 2 vols. New York: Greenwood Press 
vitória de outro. Utilizando essa demonstração, o vitorioso afirma dispor completamente do adversário através do seu corpo. A cabeça do inimigo, prova cabal da vitória, converte-se também num signo que a reifica, que a torna visível e sensível, imprimindo-a nas mentes de todos a quem tal exibição pudesse ser dirigida.

Estas observações servirão aqui como mote a um estudo, mais específico, de um caso que permite observar, num contex to histórico concreto, um exemplo da construção do imaginário acerca do rei no império neo-assírio. Este rei idealizado, Assurbanípal, será contrastado com a imagem mais mundana de outro monarca que era, não apenas estrangeiro, mas também inimigo da Assíria (logo, um «anti-rei»): Teumman, rei do Elam. De tal comparação resulta inevitável a derrota do Elamita, cujo destino seria catastrófico: desmascarado e exposto pela retórica assíria, também o relato da sua morte violenta e os seus restos mortais foram utilizados como veículos de propaganda, uma oportunidade para reforçar a feição imaginada, positiva, poderosa e legítima do rei da Assíria. Este tema do argumentário político neo-assírio surge em representações visuais e textuais elaboradas entre os séculos X e VII a.C. A decapitação de Teumman durante a batalha de Til Tuba, e a representação de escribas assírios, inventariando o número de inimigos mortos através da contagem das suas cabeças empilhadas, são dois aspetos diferentes do mesmo topos visual, embora com significados opostos, que alternam entre conhecimento (epistème) e oblívio, atributos de vitória e de derrota, respetivamente.

\section{O TEATRO DA VIOLÊNCIA.}

A guerra e a vitória militar eram temas privilegiados na representação do poder nos mais variados contextos geográficos e culturais do Próximo Oriente antigo. Nesse âmbito temático geral, a violência e a mutilação de inimigos derrotados eram elementos retóricos frequentes no registo iconográfico e textual. A guerra e a sua violência, conduzida pelo poder, integravam um discurso que acentuava a componente militar da realeza, refletindo a capacidade do soberano de conservar e alargar, não apenas o território, mas também a disponibilidade de recursos materiais. Refletia também, de uma forma apologética, a imposição da paz doméstica e da tranquilidade externa pelo uso da força. Tal discurso expressava uma cultura política com elementos comuns em vários contextos no Próximo Oriente, pese embora as diferenças culturais, por vezes profundas, entre regiões como o Egito, a Síria ou a Mesopotâmia.

A decapitação do inimigo, enquanto topos iconográfico, seria algo incomum na Mesopotâmia, ao contrário do que sucedia, por exemplo, em certas regiões da Síria. Neste quadro, o tema constituiria mais um dos vetores da influência cultural siro-hitita sobre a Assíria, como foi exposto por Rita Dolce que, 
seguindo caminhos abertos por Irene J. Winter ${ }^{2}$, fornece uma perspetiva acerca da adoção do tema do inimigo decapitado nas inscrições reais e na iconografia assíria. Como modelos e antecedentes para esta influência artística e discursiva, Dolce refere peças iconográficas sírias como o «estandarte» de Ebla ou esculturas produzidas no reino siro-hitita de Carchemišs ${ }^{3}$.

$\mathrm{Na}$ Assíria, de facto, este tema começa a ser mais identificável nas inscrições reais ao mesmo tempo que, pela primeira vez, surge o género analístico, durante o reinado de Tiglat-Falasar I ${ }^{4}$. Desde então, vários reis assírios relatam nas suas inscrições, com maior ou menor frequência, as crueldades, incluindo a decapitação, infligidas sobre os inimigos derrotados. Apesar de tais atos não serem praticados de forma sistemática, mas seletiva, de acordo com o grau de ofensa cometida contra o poder assírio e a relação com ele pré-existente ${ }^{5}$, a sua representação nos programas artísticos e nas inscrições reais passam a assumir alguma preponderância.

Aššurnașirpal II foi um dos reis que utilizou com maior fulgor, nos seus textos analísticos, o relato das sevícias punitivas perpetradas contra populações hostis. É possível citar como exemplo uma campanha que este efetuou contra o reino de Bît-Adini, durante a qual ordenou o esfolamento de um grande número de oficiais e soldados. Ao próprio rei inimigo a mesma medida foi aplicada, antes de os seus restos mortais serem exibidos como sinal de vitória ${ }^{6}$. Referindo-se a outra ocasião, Aššurnașirpal II apresenta mais um exemplo de um rol mais diversificado de tormentos cometidos contra inimigos insubmissos:

"Queimei muitos cativos entre eles. Capturei muitos soldados vivos: a alguns, cortei os braços e as mãos; a outros, cortei os narizes, as orelhas e as extremidades. Arranquei os olhos de muitos soldados. Fiz uma pilha com os vivos e uma outra com cabeças. Pendurei as suas cabeças em árvores, em torno da cidade.» ${ }^{7}$

Num dos relevos esculpidos do palácio de Aššurnașirpal II, em Kalhu, é possível observar uma cena na qual cabeças de inimigos são objetos de mofa: tal como num jogo, soldados assírios descontraem atirando-as uns para os outros. Enquanto decorre tal brincadeira, músicos tocam os seus instrumentos, conferindo um certo lirismo à cena de escárnio do inimigo ${ }^{8}$.

2 Dolce 2004, 121-32; Winter [1982] 2010, 1:525-62. Ver também Reade 1979, 335; Harmanşah 2007, 69-99.

${ }^{3}$ Ver as figs. 5-11 em Dolce 2004, 124-29.

${ }^{4}$ Grayson 1981, 38; Tadmor 1997, 325-38 (especialmente 327-28); Liverani 1988, 763-65.

${ }^{5}$ Reed 2007, 106. Cf. Reade 1979, 332-34.

${ }^{6}$ RIMA 2, A. 0.101.1, i 89-93.

${ }^{7}$ RIMA 2, A. 0.101.1, i 116-18.

${ }^{8}$ British Museum, BM 124550 (fig. 1). 
Todavia, a punição de um vencido constituía, geralmente, um espetáculo público mais sofisticado. Como este, que terá tido lugar no reinado de Assaradão, após a sua vitória contra Sarduaris, rei do Urarțu, e Abdi-Milkuti, rei de Sídon, aliados contra a Assíria:

«Para que o poder de Aššur, meu senhor, se tornasse manifesto, pendurei as suas cabeças nos ombros dos seus nobres e, com cânticos e música, desfilei pela praça de Nínive.»"

Além da apropriação do saque obtido pela guerra, o esfolamento, a imolação, a mutilação de olhos e membros, sem esquecer a decapitação, eram alguns dos atos que os textos descreviam e que materializavam, de forma pungente, a força do mando da Assíria. Tais suplícios eram cometidos como castigos, mas também serviam o intuito de propagar uma mensagem intimidatória junto de inimigos externos, fossem estes reais ou meramente potenciais. Pretendia-se, assim, que a fama do poder assírio precedesse a marcha dos seus exércitos. A essas ações bem se adequa a expressão de A. T. Olmstead que, há muitas décadas, qualificou este tipo de discurso e de exercício de poder, praticado pelos Assírios, como um modo de calculated frightfulness ${ }^{10}$.

Esta brutalidade exercida pelo poder, que ocorria sem dúvida no plano da realidade e era projetada no plano da representação literária e iconográfica, adequa-se à qualificação de «festa punitiva» que Michel Foucault atribuiu à pena e tortura capital aplicadas nos contextos por ele estudados ${ }^{11}$. Entre os objectivo da teatralização em torno de muitos suplícios infligidos sobre os corpos de soldados e reis inimigos não estaria alheia a tentativa de gerar o temor e de dissuadir as revoltas, um dos «efeitos positivos» que Foucault postula surgirem com a demonstração da capacidade de violência do poder.

Esperar-se-ia que esses efeitos fossem gerados, no contexto assírio, pela exibição da violência como "tática política»" ${ }^{12}$, que passaria também, em último plano, pela execução de um programa artístico e pela utilização de uma retórica textual e visual que induzisse determinados comportamentos por parte dos seus recetores ${ }^{13}$.

Os efeitos da continuidade do emprego destes mecanismos de intimidação ao longo da expansão assíria podem ser exemplificados por um trecho extraído

${ }^{9}$ ARAB II, $\$ 514$.

${ }^{10}$ Olmstead 1918, 209-63.

${ }^{11}$ Foucault 1975, 15.

${ }^{12}$ Foucault 1975, 31.

${ }^{13}$ Essas reações seriam, naturalmente, distintas consoante os observadores, fossem estes membros da elite próxima do poder, pessoas de baixa extracção que tivessem o privilégio de entrar num palácio assírio, ou mesmo dignitários, reféns ou prisioneiros estrangeiros: reverência ou identificação, por parte de uns; temor e admiração por parte de outros. 
da célebre Carta ao deus Ǎšur, documento redigido no reinado de Sargão II. Este texto pertencente ao género literário das «cartas aos deuses» relata a sua oitava campanha, desencadeada contra as regiões montanhosas que rodeavam a Assíria, junto ao Urarțu e à Média. Um trecho escolhido serve como demonstração do efeito dissuasor que se esperava provocar pela fama da capacidade militar assíria:

«Contra Parsuaš me dirigi. Os chefes da terra de Namri, Sangibuti, BîtAbdadani e da terra dos poderosos Medos, sabendo da vinda da minha expedição - como a devastação das suas terras, que tivera lugar no ano anterior, estava ainda na sua memória, o terror abateu-se sobre eles.» ${ }^{14}$

A menção a estas brutalidades exercidas sobre os vencidos surge nas fontes textuais, geralmente após a referência à ação bélica propriamente dita. Não se tratando assim de atos de guerra tout court, seriam entendidos também como a execução de uma decisão judicial equivalente à pena capital (dîn napištim), uma das prerrogativas que, na Mesopotâmia, era tradicionalmente exclusiva do rei. Por isso mesmo, num diferente nível semântico, «crime» e «criminoso» eram expressões aplicadas também a inimigos externos, sobre os quais recairia a «pena» ou castigo «judicial» - a guerra punitiva cuja execução se concebia como autorizada, encorajada e confiada pelos deuses ao rei ${ }^{15}$.

De facto, do ponto de vista ideológico, o rei assírio afirmava-se como «o rei que, com a ajuda de Aššur e de Šamaš, os deuses que nele confiam, age justamente», šarru ša ina tukūlti d Aššur u d ${ }^{\mathrm{S} a m a s ̌ ~}$ ilāni tikli-šu mešeriššr, ou como o "guardião do que é correto e amante da justiça», nașir kitti u ra’im mešari ${ }^{17}$. Neste sentido, a guerra não era apenas concebida como fenómeno unicamente situado num plano político e militar, mas apresentada como a justa retribuição perante um casus belli, cuja culpa recairia sempre no adversário, segundo o discurso ideológico estruturante das inscrições reais ${ }^{18}$. O inimigo era visto como um «criminoso», um "pecador», o único responsável pelo seu próprio castigo, sofrido às mãos do rei assírio, que mais não faria do que agir como verdugo dos deuses na terra $^{19}$. Senaquerib justifica desta forma a sua primeira campanha, desencadeada

${ }^{14}$ Extraído da edição de Thureau-Dangin 1912, 39.

${ }^{15}$ Uma síntese fundamental sobre a guerra como ato de justiça, em Oded 1992, 29-44.

${ }^{16}$ Aššurnașirpal II: RIMA 2, A.0.101.1, i 22.

${ }^{17}$ Senaquerib: OIP 2: 23, H2, i 4-5.

${ }^{18}$ Oded 1992, 30.

${ }^{19}$ Tal conceção do monarca como instrumento, como arma de guerra utilizado pela divindade é um elemento comum nas culturas do Próximo Oriente antigo. Ressurge com frequência no Antigo Testamento, por exemplo, no oráculo do profeta Isaías contra os Assírios, que são designados, pelas palavras de Yahweh, como «vara da minha cólera», «bastão do meu furor» e como um «machado» manejado pelo próprio Deus (Is. 10, 5-16). Cf. o versículo em que Yahweh vitupera a hybris do rei da Assíria que, na perspetiva do profeta bíblico, contraria a confiança nas 
contra os rebeldes caldeus na Babilónia, comandados por Marduk-apla-iddina, líder da tribo de Bît-Yakīn. Este é apresentado como um «[instigador] de revoltas [baranū], um maquinador de traição [karaš surrāti], causador de males [epeš limutti], cuja vilania é grande [ša anzilla-šu kabtu $]{\aleph^{20}}$.

Seguindo Bustenay Oded, pode entender-se este contraste entre os atributos do soberano assírio com os dos seus adversários como um elemento moral de justificação para a guerra. Legitimar-se-ia, assim, a expansão militar através de «argumentos éticos» que a explicavam e enquadravam numa conceção de "guerra justa» ${ }^{21}$. Esses argumentos faziam parte de um discurso e de uma retórica que refletia os parâmetros ideológicos que sustentavam a expansão militar assíria, não apenas por intermédio de textos, como as inscrições reais, mas também com o recurso a imagens e peças monumentais que preenchiam os palácios assírios ${ }^{22}$.

\section{Assurbanípal vs. Teumman.}

Um dos conjuntos monumentais assírios mais importantes, pela sua riqueza narrativa e execução artística, é constituído por vários ortóstatos esculpidos em baixo-relevo que pertenciam ao Palácio Sudoeste de Nínive, construído por Senaquerib. Este complexo palaciano fora utilizado mais tarde pelo seu neto, Assurbanípal, que nele concentrou também os esforços da sua produção simbólica. Parte desse esforço resultou nos relevos que retratam a batalha de Til Tuba, travada contra os Elamitas no ano de 653 (ou 664) a.C., episódio culminante de uma conjuntura agitada no quadro do difícil relacionamento entre a Assíria e o Elam $^{23}$.

Após um período de paz, inaugurado ainda no reinado de Assaradão ${ }^{24}$, Urtaku, rei do Elam, fora deposto por um indivíduo chamado Teumman, que se dispôs a desencadear o conflito latente com a Assíria. Teumman é designado com

divindades e conta apenas com a sua arrogância e poder: «Acaso gloriar-se-á o machado contra quem o maneja?» (Is. 10,15), i.e., o rei mortal contra a entidade divina que o instrumentaliza.

${ }^{20}$ OIP 2.48, A1, 6.

${ }^{21} \mathrm{O}$ objectivo desta argumentação era, segundo Bustenay Oded, «...to endow moral sanction to Assyrian violence by presenting it as the punishment for evildoers» (Oded 1992, 44).

22 Reade 1979, 329-43; Bachelot 1991, 109-28; Ataç 2006, 69-101. Algumas publicações sobre os relevos assírios: Barnett 1970; Reade 1998 e Collins 2008.

${ }^{23}$ British Museum, ME 124801a-c figs. 2-4. Sala XXXIII do palácio Sudoeste de Nínive. Ver Reade 1979, 329-43; Watanabe 2004, 103-14; Reed 2007, 101-30; Bahrani 2008, 22-55; sobre a batalha, consultar Fales 2010, 202-5, que defende a data de 664 a.C. Uma síntese da conjuntura e das relações entre a Assíria e o Elam: Brinkman 1965, 161-66; Boardman et al. 1991, 47-53, 147-54.

${ }^{24}$ Um inquérito oracular (SAA IV, 74) dirigido ao deus Šamaš, pedido por Assaradão, mostra as dúvidas que o lado assírio alimentava sobre a sinceridade da oferta de paz enviada por Urtaku, rei do Elam: «Šamaš, grande senhor, dai-me uma resposta firme e positiva sobre o que eu vos estou a perguntar: se Urtaku, rei do Elam, enviou a sua proposta para fazer a paz com Assaradão, rei da Assíria - enviou ele, na verdade do seu coração [ina kitti libbi-šu], palavras verdadeiras e honestas de paz a Assaradão, rei da Assíria?» 
desprezo por Assurbanípal como alguém «semelhante a um demónio», tamšil

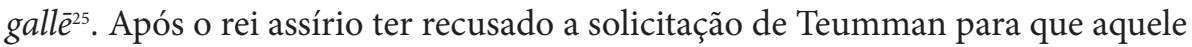
extraditasse para o Elam os filhos do rei elamita deposto, refugiados na Assíria ${ }^{26}$, travar-se-ia uma batalha em Til Tuba, um local situado nas margens do rio Ulaya, já bem no interior do Elam.

A batalha é vividamente retratada nos relevos do Palácio Sudoeste de Nínive, através de uma composição narrativa complexa e dinâmica, com um grande cuidado no detalhe nos seus elementos figurativos e em cenas individualizadas que retratam a violência do combate ${ }^{27}$. Por toda a parte, soldados elamitas são chacinados e empurrados para o rio, que transporta inúmeros cadáveres na sua correnteza. O próprio Assurbanípal afirma que, «com os seus cadáveres, bloqueei o rio Ulaya. $»^{28}$

Neste sentido, o combate, um acontecimento histórico, e as águas do rio, elemento físico e concreto de uma paisagem real, servem como perfeitas metáforas para a função intemporal atribuída à realeza de combater o caos e expulsar o inimigo da ordem civilizada, que o rei tinha a obrigação de estabelecer ou restaurar. Este elemento aquático, para onde era empurrado o exército elamita, levava os mortos expulsos de volta para a esfera do caos, do indistinto, identificando-se de algum modo com a ação de um «dilúvio» (abūbu).

Assurbanípal, o rei assírio, está, no entanto, ausente dos relevos que expõem o combate de Til Tuba. Pelo contrário, em todo o conjunto da composição, Teumman é um elemento constante. O rei do Elam, e a sua cabeça, surgem em várias ações que ocorrem ao longo da composição. Decapitado diante do próprio filho ${ }^{29}$ por um soldado comum, a sua cabeça é transportada, ao longo de vários momentos da narrativa visual, para ser entregue ao rei assírio. O momento em que se consuma tal encomenda não surge representado visualmente, mas tal se afirma textualmente nos anais de Assurbanípal ${ }^{30}$ e na epígrafe inscrita sobre uma das cenas da batalha, que representa um soldado, servindo agora como correio, transportando velozmente a cabeça:

«Cabeça de Teumman, rei do Elam, que no meio da batalha, um soldado comum do meu exército cortou. Para me dar as boas novas, despacharam-na velozmente para a Assíria.» ${ }^{31}$

\footnotetext{
${ }^{25}$ Piepkorn 1933, 60-61, B, iv 74.

${ }^{26}$ Piepkorn 1933, 61-63, B, iv 87-99.

${ }^{27}$ Ver abaixo, figs. 2-4.

${ }^{28}$ Piepkorn 1933, 68-69, B, v 97. Ver ARAB II, § 1072; Russell 1999, 159, 35.

${ }^{29} \mathrm{O}$ seu filho, Tammaritu, sofreria o mesmo destino que o pai: «Com o encorajamento de Aššur e Ištar, matei-os. As suas cabeças eu cortei um diante do outro.» (Gerardi 1988, 31).

${ }^{30}$ Piepkorn 1933, 61, B, vii 61: «...a cabeça cortada de Teumman, que um soldado comum do meu exército decapitou...», nikis qaqqadi Teumman ša ikkisu ahurū ummanatē-ia.

${ }^{31}$ Citado a partir de Gerardi 1988, 29. Cf. Russell 1999, 159, 10a.
} 
De facto, a cabeça do malogrado rei elamita é a componente principal de todos os painéis, aos quais confere coerência narrativa ${ }^{32}$. A sua importância, enquanto princípio fundamental de toda a composição, é reafirmada, porém, em outro painel de relevo, celebrizado pela designação de Cena do Banquete: neste relevo, em abrupto contraste com a desordem violenta da batalha, Assurbanípal e a sua consorte são representados em ameno bivaque num espaço pacífico, nos jardins de um palácio, onde aves, plantas e árvores, servos e músicos compõem uma cena que se pode qualificar como idílica ${ }^{33}$. No interior desse espaço de tranquilidade, a cabeça de Teumman surge pendurada numa árvore, introduzindo na composição um aspeto contraditório. Que níveis de significado se podem aferir de todo este conjunto artístico?

A cabeça de um rei, no plano simbólico, é uma sinédoque representando a sua comunidade de súbditos, a sua verdadeira, quase literal, caput regni. Por este motivo, o rei assume uma qualidade abstrata, idealizada ou imaginada. Se essa imaginação acerca do rei incorre num certo grau de objetificação por parte de muitos dos que com ele convivem e que à sua volta gravitam em proximidade, ela tornar-se-ia mais forte, pelo contrário, à medida que o sujeito que o imagina se acha social e geograficamente mais distante. Essa abstração, de um modo comum aos mais diversos contextos históricos e culturais do poder político, seria encorajada pelos rituais do poder, pelo protocolo e outros mecanismos sociais que instituíam, jurídica e socialmente, essa distância entre o soberano e os outros seres humanos, incluindo os seus súbditos ${ }^{34}$.

A cabeça do rei do Elam, que governava um país distante, hostil e poderoso, possuiria certamente essa feição indistinta e imaginada nas mentes dos Assírios que, a dado momento, se tornaram seus inimigos. A sua força, como ideia, seria naturalmente maior entre os soldados comuns do exército assírio que, ao contrário das elites e populações residentes nas capitais, teriam também pouco ou nenhum conhecimento direto e concreto do seu próprio soberano, Assurbanípal, também ele envolto numa espécie de «névoa» ritual, sacra e protocolar do poder ${ }^{35}$.

Teumman surge representado em modo metafórico no relatório de um oráculo remetido a Assurbanípal, relacionado diretamente com esta conjuntura de conflito. O Elamita parece ser comparado a uma serpente (șerru), que o deus comunica o oráculo teria arrancado do interior de uma arma (uma maça ou bastão, nar'amtu) e «cortado aos pedaços»:

«Palavras sobre os Elamitas: [o] deus diz assim: "Fui e vim". Ele disse cinco vezes, seis vezes e depois: "Vim do bastão. Arranquei a serpente que estava no

\footnotetext{
${ }^{32}$ Watanabe 2004, 103-14.

${ }^{33}$ British Museum, ME 124920 (fig. 5). Consultar Bahrani 2008, 22-55.

${ }^{34}$ Liverani 1979, 302-3.

${ }^{35}$ Acerca da vida do rei em contexto de corte, consultar Liverani 2009, 81-91.
} 
seu interior, cortei-a aos pedaços e quebrei o bastão." Ele disse: "Destruirei o Elam. O seu exército será arrasado ao nível da terra." "»6

Através deste oráculo, a divindade assegurava ao rei assírio que o inimigo, como um animal dissimulado e perigoso (uma serpente escondida dentro de uma arma), seria derrotado e deixaria de representar uma ameaça. Esta metáfora, não referindo a decapitação do Teumman, parece situar-se num momento anterior à sua morte em batalha e à derrota final do Elam em Til Tuba. Porém, é sugestiva acerca do modo como o inimigo era comparado com uma serpente cuja decapitação poderia trazer a vitória à Assíria ${ }^{37}$.

A decapitação de Teumman adquire assim um valor simbólico poderoso: o Elam, a entidade coletiva que o sustinha, perde a sua caput régia, o que significa a perda simbólica da sua identidade política e da sua independência. Este ato promove uma alteração na qualidade de ente imaginado do rei elamita: a partir do momento em que este perde a vida e a cabeça nas margens do Ulaya, a sua dimensão abstrata começa a desvanecer-se. Teumman, o rei do Elam, transformase gradualmente, aos olhos dos seus inimigos e conquistadores, em Teumman, um homem.

A apropriação final do corpo de Teumman é demonstrada nos textos onde Assurbanípal faz relatar como cuspiu na sua cabeça cortada ${ }^{38}$; como a exibiu na cidade de Arbela ${ }^{39}$ e pelas ruas de Nínive, colocando-a aos ombros de Dunānu, um dos aliados de Teumman que foram capturados ${ }^{40}$. Em pompa triunfal, por entre música e «alegria», o saque do Elam e os inimigos da Assíria foram assim exibidos perante a população:

«A cabeça de Teumman, rei do Elam, pendurei ao pescoço de Dunanu (...) Com o saque do Elam e os despojos de Gambulu que, ao comando de Aššur, as minhas mãos capturaram - com cantores e música, entrei em Nínive, por entre exclamações de alegria [ina hidāte].» ${ }^{41}$

Assurbanípal terá depois consagrado a cabeça do seu inimigo aos deuses, efetuando sobre ela libações de vinho, em contexto ritual ${ }^{42}$. É notória a semelhança deste ato com as libações efetuadas sobre os cadáveres dos leões mortos

\footnotetext{
${ }^{36}$ SAA IX, 8 (tradução portuguesa em Caramelo 2002, 205-6).

37 Sugestão de Francisco Caramelo. Acerca dos oráculos assírios acerca desta conjuntura político militar, consultar Caramelo 2002, 232-40.

${ }^{38}$ Bonatz 2004, 94; Russell 1999, 160, 11.

39 Sobre a parada em Arbela, ver referências em tabuinhas cuneiformes que se planeavam transpor para epígrafes de relevos, em ARAB II, $\$ \$ 1041,1043,1045$ e 1071.

${ }^{40}$ Ver imagem 66 em Russell 1999, 181 = British Museum, ME 124802.

${ }^{41}$ Piepkorn 1933, 72-73, B: vi 50-56. Ver Russel 1999, 160-61.

42 Bonatz 2004, 98-99; Russell 1999, 161, 14.
} 
pelo rei assírio, conforme é visível em vários dos seus relevos que representam a caça como actividade régia ${ }^{43}$. A este propósito, afirma Dominik Bonatz que a oferta da cabeça de Teumman aos deuses seria um ritual político inaugurado por Assurbanípal, que introduz assim, de forma algo destoante, uma actividade «primitiva» no seio de uma sociedade urbana e estatal complexa ${ }^{44}$.

Estas manifestações rituais, em agradecimento aos deuses, seriam consideradas como a prova cabal, do ponto de vista ideológico e religioso, da justiça da causa de Assurbanípal e do apoio divino a ele dispensado. O rei assírio, aliás, teria recebido a resposta às suas preces e dúvidas através de consultas oraculares:

«Ištar ouviu os lamentos que lhe dirigi e disse: "Não temas!" [la tapallah!], e confortou o meu coração.»

Pelo contrário, ao rei elamita teriam surgido presságios nefastos: dizem os textos assírios, provavelmente com engenho criativo e retórico, que um eclipse surgira no Elam, prevendo a sua derrota ${ }^{45}$, e que um acidente teria deixado Teumman com alguns problemas de saúde. $\mathrm{O}$ incauto Teumman, apresentado como descrente do poder dos deuses ou, pelo menos, convencido que teria a sua ajuda, teria ignorado todos estes avisos; a sua própria má-fé e imoralidade teriam atraído a vingança divina: «Teumman maquinou males [limutti]; o deus Sîn planeou para ele portentos nefastos.» ${ }^{46}$

A sua derrota e decapitação seriam o corolário da sua impiedade e atos de injustiça. É então que aquilo que era indistinto, abstrato, imaginado (Teumman, rei do Elam), se transformava em algo público e conhecido: as suas feições reais, incluindo as suas características físicas concretas e próprias (por exemplo, as rugas, a textura e cor da pele, eventuais assimetrias do rosto) ${ }^{47}$, tornam-no, aos olhos dos que o podem agora contemplar na sua destruição, num ser humano exposto no seu momento mais frágil e vulnerável. A exibição pública da cabeça do rei elamita destrói o mito da sua realeza, mas não a sua identidade humana, em contraste com o soberano assírio, a quem os deuses teriam conferido «força, virilidade e um exaltado poder», dunnu, zikrūtu, emuqān șirāt $i^{48}$. Ao contrário do que defende Davide Nadali relativamente à representação do «inimigo» em geral, Teumman não é vítima de um annullamento ${ }^{49}$. Pelo contrário, a exibição triunfal

${ }^{43}$ Como é notado por Bonatz 2004, 98. Ver Reade 1998, 72-79.

${ }^{44}$ Bonatz 2004, 100.

${ }^{45}$ Piepkorn 1933, B: v 4-8. Ver Apêndice de Joachim Mayr, na mesma obra, 105-9.

${ }^{46}$ Piepkorn 1933, 62-63, B: v 3-5.

${ }^{47}$ Os painéis revelam um pormenor interessante: a representação da cabeça de Teumman revela uma certa calvície, depois de cair o seu capacete. É especialmente visível em ME 124801a $($ registo superior $)=$ fig. 4 .

${ }^{48}$ Piepkorn 1933, 28-29, B: i 11.

${ }^{49}$ Nadali 2011-2003, 53-57. 
dos seus restos mortais iluminava aquilo que, por ser apenas imaginado, estava oculto. Expõe-se, assim, aquilo que, na perspetiva assíria, era um comportamento subversivo e hostil, uma obstinação ilegítima na fuga ao controlo pelo rei assírio, não pertencendo ao domínio da ordem e do cosmos. Teumman, ao deixar de ser apenas uma ideia ou personagem imaginado de um rei inimigo estrangeiro, passa a ser algo conhecido, logo, conquistado. A vitória obtida contra ele e contra o Elam adquiria assim uma dimensão "epistémica», que se pode abstrair através da metáfora da exposição e manipulação impune dos seus restos mortais ${ }^{50}$.

A fase final deste processo de humanização ou banalização de Teumman é, não obstante, rica em significado. A representação onde o rei assírio é retratado em convivência tranquila com a sua consorte no jardim, rodeados de músicos, aves e plantas, inclui a imagem da cabeça do malogrado rei elamita pendurada numa árvore como troféu $\mathrm{u}^{51}$. O propósito deste contraste é óbvio: ao caos da batalha de Til Tuba, nas margens de um rio transformado em escoadouro de cadáveres, num espaço de desordem e confusão, e onde o rei inimigo ainda surge como um ser vivente, sucede a ordem e a tranquilidade representada pelo jardim onde Assurbanípal beberica com a sua esposa. Nesse jardim, Teumman ainda existe, mas apenas enquanto resto mortal; só com o inimigo neste estado, derrotado, morto e banalizado, seria possível o advento da paz e a construção de um espaço político e cósmico de ordem. Pois enquanto aquele respirasse, seriam a chacina, o combate e a morte a imperar.

A utilização do espaço como elemento discursivo não é verbalizada de modo explícito; porém, torna-se evidente que os lugares, de algum modo, se transformam em atributos da realeza - o jardim de Assurbanípal é um símbolo ou uma metáfora para o ideal do mundo controlado pela Assíria: ameno, próspero, fecundo, pacato ${ }^{52}$. Em oposição, o lugar onde se desenrola a batalha contra os Elamitas, situado fora dos domínios assírios, é um espaço de morte, de fuga em estouro; nele corre um rio, o Ulaya, que, como o Lethes romano, faz escorrer para o $a p s \hat{u}$, i.e., para o esquecimento, para o torpor do oblívio que caracterizava o marido de Tiamat, as veleidades de Teumman em comparar-se a Assurbanípal.

\section{VENCER: FAZER ESQUECER.}

Em certos contextos do Próximo Oriente antigo, decepar e reunir partes dos cadáveres de soldados inimigos, como um meio de facilitar a contagem das baixas infligidas, parece ter sido uma prática comum. Recordemos o Egito, em que era costume cortar, não somente as mãos direitas dos inimigos mortos, mas

\footnotetext{
${ }^{50}$ Liverani 1979, 307.

${ }^{51}$ Bonatz 2004, 99-100 (cf. Caramelo 2003, 92).

${ }^{52}$ Ver as observações em Caramelo 2003, 92.
} 
também os seus órgãos sexuais. A espoliação da virilidade e da força vital do inimigo deverá ser vista como um instrumento de carácter «mágico-punitivo» que consubstanciava a vitória ${ }^{53}$.

$\mathrm{Na}$ arte palaciana assíria, a decapitação do inimigo como elemento discursivo e propagandístico é ainda patenteada em cenas que representam uma dupla de escribas fazendo o trabalho de contagem de cabeças cortadas. Este topos visual aparece em diversos relevos assírios, a maior parte deles originários do Palácio Sudoeste de Nínive. A contagem das cabeças, e não dos corpos, parece ter sido uma forma de facilitar esse inventário, já que nessas representações, as cabeças são empilhadas diante dos escribas. Efetuando um gesto de contagem, estes registam as quantidades aferidas em tabuinhas de argila, folhas de pergaminho ou papiro, e em «tábuas de cera» $(l \vec{e} u)^{54}$.

Ao contrário da decapitação de Teumman, cujo significado político e simbólico é evidente, nestes exemplos, entendidos a partir de uma análise preliminar descritiva, a ação que intentam representar aparenta ser mais prosaica, não possuindo qualidades simbólicas especiais ${ }^{55}$. Na aparência, tratar-se-ia de um ato puramente administrativo, pois os exércitos assírios em trânsito contavam com escribas que cumpriam tarefas burocráticas e logísticas, tais como o racionamento e distribuição de equipamento, o registo de tributos e de saque, e mesmo o registo de baixas, tantas as próprias como as do inimigo ${ }^{56}$.

No entanto, a análise deste tema iconográfico permite-nos alcançar outros níveis de significado. Um deles é a vitória sobre o inimigo por via da sua decomposição ou dissolução. O conteúdo semântico destas imagens pretendia mostrar que o exército inimigo, ainda que numeroso, passara a ser atomizado pela acumulação das suas baixas em pilhas disformes. É disso sintomático que, em várias dessas imagens, as cabeças decapitadas surjam em associação com os frutos do saque efetuado pelos Assírios, como armas, mobiliário e toda a sorte de outros bens ${ }^{57}$.

Reduzir o inimigo a um objecto de tratamento estatístico equivalia a transformá-lo numa entidade anónima ${ }^{58}$. Tal é a interpretação de Davide Nadali, que postula, acertadamente, que as cabeças dos guerreiros adversários, antes isoladas mas integradas na completude física do seu ser e corpo, perdem a sua personalidade e individualidade ao serem acumuladas como objetos. Misturando-se, confundindo-se com múltiplas outras identidades numa massa amorfa, o

${ }^{53}$ Segundo Araújo 2010, 102-4.

${ }^{54}$ Dois exemplos de imagens de relevos do British Museum: BM 124955-7, de Senaquerib (fig. 6) e ME 124825 (fig. 7), de Assurbanípal. Sobre este tema iconográfico, consultar ainda Russell 1991, 292, nota 36; e o trabalho mais recente de Julian Reade (Reade 2012).

${ }^{55}$ Bonatz 2004, 99.

${ }^{56}$ Saggs 1963, 148; Reade 2012.

${ }^{57}$ Fig. 7, ME 124825. Cf. Nadali 2001-2003, 66.

${ }^{58}$ Bonatz 2004, 93. 
inimigo torna-se, segundo as palavras de Nadali, «irreconhecível e reduzido a um mero objecto» sobre o qual incidia a ação militar assíria ${ }^{59}$.

Esvaziando-se a identidade do inimigo desta forma simbólica, pode assim notar-se uma metáfora para a imersão no "caos primordial», em que a inexistência das coisas se definia, antes de mais, pela ausência de uma forma, de um nome, de uma identidade. De facto, se Teumman, um inimigo com um estatuto régio, pode ser visto ainda como um personagem importante na narrativa construída pelos produtores destas representações textuais e visuais, os seus soldados, pelo contrário, poderão ser nelas considerados como meros figurantes. Esta indistinção ou perda de individualidade do inimigo através da morte equivale ao seu oblívio. Neste contexto, o esquecimento absoluto do derrotado constituía uma inversão da possibilidade que o vitorioso dispunha de perpetuar os seus «feitos» através da celebração monumental, do registo literário e da construção da sua memória - isto é, da sua sobrevivência para lá da morte.

Reflexos sobre o oblívio do inimigo como um estado equiparado à sua morte absoluta surgem amiúde nos textos analísticos. A sua fuga, ainda que bem-sucedida, pode ser entendida como uma «saída de cena» da História, de acordo com a visão oficial assíria. Sargão II, no seu oitavo palû (714 a.C.), durante a sua campanha militar contra Manneus e Medos, derrotou Mitatti da terra de Zikirtu. Depois de a sua capital, Parda, ser destruída, Mitatti fugiu com o seu povo «para não mais ser visto» ${ }^{60}$.

Por sua vez, Šuzubu, alias Mušēzib-Marduk, líder dos rebeldes caldeus, teria fugido sozinho durante a quarta campanha do reinado de Senaquerib (700 a.C.) O pavor causado pela perspetiva de uma batalha contra os exércitos assírios tê-lo-ia feito escapar sozinho, nunca mais tendo havido notícia do seu paradeiro: «Ele fugiu sozinho, como um lince [kima azari], e nunca se soube o seu paradeiro. $»^{61}$

O oblívio, contudo, poderá não ser apenas considerado como metáfora para a morte ou fuga apavorada do inimigo: como resultado da conquista e da vitória sobre o adversário, a deportação de populações é também envolvida num discurso ideológico que lhe pode ser associado ${ }^{62}$. Esta prática, que se tornou bastante mais usual a partir do reinado de Tiglat-Falasar III ${ }^{63}$, consistia na deslocação forçada de comunidades que viviam em territórios conquistados pelos Assírios e tornados depois em províncias, como meio de punição, de aproveitamento de

\footnotetext{
${ }^{59}$ Nadali 2001-2003, 66: «...numerosi corpi acefali e denudati di nemici ormai irriconoscibili e ridotti a meri oggeti...»

${ }^{60}$ ARAB II, \$19; Fuchs 1993, 110, Ann. \$127.

${ }^{61}$ RINAP 3/1, no 15, 1s. iv 23. Se Šuzubu escapou como «um lince», um animal selvagem, Lulî, rei de Sídon, havia fugido, no ano anterior (701 a.C.), para Chipre, «como um peixe», kima nūni iparšid...

${ }^{62}$ Nadali 2001-2003, 56-57.

${ }^{63}$ A melhor síntese sobre este tema: Oded 1979.
} 
recursos humanos e como forma de destruir a identidade política da comunidade afetada. As populações deportadas, espoliadas da sua personalidade própria enquanto membros de uma entidade política, passavam a ser integradas no interior do mundo controlado pelos Assírios, concebido como um espaço onde imperava a ordem exigida para o equilíbrio cósmico e terreno.

Ao nível discursivo, a ideia dessa integração podia ocorrer, por exemplo, na absorção dos deportados pela própria população assíria. Tal é refletido na expressão «...contei-os entre as gentes da Assíria», itti nišē māt Aššur amnu-šunūtít ${ }^{64}$. Estas expressões convencionais revelam que, de algum modo, estas gentes eram consideradas subsumidas, imersas, ainda que ao nível discursivo e ideológico, no conjunto dos súbditos do soberano. Importa referir que a deportação era um momento privilegiado para a atuação dos escribas assírios, pois as deslocações de pessoas por territórios vastos implicavam um aparato logístico sofisticado e um esforço organizativo acentuado para a sua realocação posterior. $\mathrm{O}$ registo escrito das famílias e indivíduos deportados, com suas origens e destinos ${ }^{65}$, é um sinal de como a sua absorção na ordem assíria era mais um aspeto da dimensão epistémica da conquista.

A estas observações, deve ser adicionada uma outra: os temas da contagem de tributos e dos restos mortais de inimigos como signos de vitória e a contagem de populações deportadas refletem não somente uma dimensão simbólica de um discurso baseado na violência, mas também uma faceta burocrática do exercício do poder. A natureza administrativa do poder complementa, ao nível discursivo, a dimensão religiosa, heroica e carismática do soberano, revelando a complexidade da ideologia e cultura política no império neo-assírio. Não era apenas o pathos da guerra - o furor, a agressividade e a coragem física dos soldados Assírios face ao inimigo - o único meio de demonstrar, como fazem os relevos ninivitas onde se espraia a batalha de Til Tuba, a capacidade e justeza do poderio da Assíria: a sua organização, enquanto estado, era um elemento racional que reforçava a sua imagem de superioridade.

\section{CONSIDERAÇões Finais.}

A exibição da cabeça de Teumman, como um dos protagonistas do programa monumental de Assurbanípal, e o tema da acumulação de cabeças de soldados inimigos mortos contribuem para banalizar e depreciar o inimigo, em

${ }^{64}$ Isto se afirma, por exemplo, acerca de Caldeus do Sul da Mesopotâmia, recolocados por Tiglat-Falasar III em diferentes províncias assírias, após as suas campanhas na Babilónia: «...e contei-os juntamente com o povo da Assíria. Sobre eles impus, tal como aos Assírios, o jugo de Aššur, meu senhor.» (ARAB I, \$ 764).

${ }^{65}$ Ver, por exemplo, os registos compilados em SAA XI, cap. 8. 
contraste com a projeção da majestade do soberano assírio e da força dos seus exércitos, cuja ação era objecto de justificação ideológica e moral.

Todavia, devemos identificar uma diferença significativa nestes dois modos de tratamento simbólico e artístico do tema do inimigo decapitado: por um lado, se Teumman, através da sua cabeça cortada, é humanizado ao ser despido da sua aura régia, ao ser-lhe retirada a máscara da realeza, os seus soldados, pelo contrário, eram desumanizados e equiparados a objetos. A sua morte equivalia à sua expulsão para o caos primordial, que o rei assírio, como qualquer soberano mesopotâmico, tinha o dever de combater ${ }^{66}$.

Entre estas duas perspetivas se observa uma tensão entre o ato de expor, de trazer à luz e conhecer o inimigo conquistado (logo, a sua transformação em algo familiar, que já não provoca tensão ou medo), e o discurso que provoca, simbolicamente, o seu esquecimento, a sua imersão no oblívio e no caos. Se, como objetos de um registo contabilístico que os agregava de modo indistinto, os comuns soldados eram despidos da sua identidade e, como tal, remetidos ao oblívio, os seus reis passariam a integrar a gesta narrativa da expansão assíria, os seus nomes recordados, como derrotados ou submetidos, nas inscrições que glorificavam os monarcas de Aššrur.

A inclusão do tema da decapitação dos inimigos nos programas artísticos dos palácios assírios constituía um ato comunicativo endereçado, não já a partir da periferia, como tática psicológica que respondia a necessidades militares directa no terreno, mas sim no centro do poder. Este controlo sobre as imagens e representações assumia-se como uma síntese de uma forma de exercício de poder, que refletia uma seleção cuidada e uma dimensão propagandística ${ }^{67}$. Seria intenção dos produtores dessas representações linguísticas e não-linguísticas (isto é, o rei e a elite mais próxima do poder) provocar determinadas respostas nos observadores. Porém, integrando-se no aparato simbólico dos palácios e capitais assírias, estes relatos e imagens adquiriam uma dimensão performativa e mágico-religiosa que traduzia, de modo mais sofisticado, os parâmetros ideológicos que o poder assírio tencionava consubstanciar. Assim, esperar-se-ia que a representação do inimigo morto, tendo mais do que apenas um propósito simbólico, o mantivesse nesse estado, de uma forma mágica ${ }^{68}$.

Nestes elementos discursivos é notório um paradoxo: o desencadear da guerra como actividade geradora de paz; a celebração da ordem cósmica providenciada pelo soberano, tornada possível apenas, muitas vezes, afrontando o ordálio caótico da batalha; e, por fim, a exposição da violência e da crueldade infligida sobre corpos humanos pelo poder instituído - algo que a desejável

\footnotetext{
${ }^{66}$ Reade 1979, 332; Nadali 2001-2003.

${ }^{67}$ Reade 1979, 329-43; Liverani 1979, 297-317.

${ }^{68}$ Nadali 2001-2003, 64; Bahrani 2004, 115-19.
} 
«normalidade» da vida social aconselha à ocultação - como forma de enaltecer a quietude de uma vida submissa e obediente. Todavia, estas contradições, assim constatadas, são apenas aparentes e, de resto, estabelecidas a partir da nossa própria perspetiva. Guerra vs. paz; ordem $v s$. caos; o rei guerreiro $v s$. o rei pastor piedoso para com o seu povo, não seriam antinomias tão óbvias na visão assíria. Estes opostos, segundo parâmetros culturais mais latos do Próximo Oriente antigo, coexistiriam na realidade mundana e divina desde a origem do mundo, fazendo parte da sua estrutura e da sua lógica mais profunda. 


\section{BibliografiA}

Araújo, Luís Manuel de. 2010. "A luta pela sobrevivência no Egipto: a expulsão dos 'Povos do Mar.'” In A Guerra na Antiguidade. Vol. 3, ed. A. Ramos dos Santos e José Varandas, 97-150. Lisboa: Centro de História da Faculdade de Letras / Caleidoscópio.

Ataç, Mehmet-Ali. 2006. "Visual Formula and Meaning in Neo-Assyrian Relief Sculpture." The Art Bulletin 88 (1):69-101.

Bachelot, Luc. 1991. "La fonction politique des reliefs néo-assyriens." In Marchands, diplomates et empereurs: études sur la civilisation mésopotamienne offertes à Paul Garelli, ed. Dominique Charpin e Francis Joannès, 109-28. Paris: Éditions Recherche sur les Civilisations.

Bahrani, Zainab. 2008. Rituals of War. The Body and Violence in Mesopotamia. New York: Zone Books.

—.2004. “The King's Head.” Iraq 66:115-19.

Barnett, R. D. 1970. Assyrian Palace Reliefs in the British Museum. London: Trustees of the British Museum.

Bonatz, Dominik. 2004. "Ashurbanipal's headhunt: an anthropological perspective." Iraq 66:93-102.

Boardman, J., I. E. S. Edwards, N. G. L. Hammond, et E. Sollberger, eds. 1991. Cambridge Ancient History. Vol. 3, parte 2, The Assyrian and Babylonian Empires and other States of the Near East, from the Eighth to the Sixth Centuries B.C. $2^{a}$ ed. Cambridge: Cambridge University Press.

Brinkman, J. A. 1965. "Elamite Military Aid to Merodach-Baladan.” Journal of Near Eastern Studies 24 (3):161-66.

Caramelo, Francisco. 2003. "Os jardins reais na Assíria: uma reprodução idealizada da natureza." Revista da Faculdade de Ciências Sociais e Humanas 15:85-92.

—_. 2002. A linguagem profética na Mesopotâmia (Mari e Assíria). Cascais: Patrimonia.

Collins, Paul. 2008. Assyrian Palace Sculptures. London: British Museum Press.

Dolce, Rita. 2004. "The 'head of the enemy' in the sculptures from the palaces of Nineveh: an example of 'cultural migration'?" Iraq 66:121-32.

Foster, Benjamin R. 1996. Before the Muses: an Anthology of Akkadian Literature. $2^{\mathrm{a}}$ ed., 2 vols. Bethesda: CDL Press.

Foucault, Michel. 1975. Surveiller et Punir. Naissance de la Prison. Paris: Gallimard.

Grayson, A. K. 1981. “Assyrian Royal Inscriptions: Literary Characteristics.” In Assyrian Royal Inscriptions. New Horizons in Literary, Ideological and 
Historical Analysis. Papers of a Symposium held in Cetona (Siena), June 26-28, 1980, ed. F. M. Fales, 35-47. Roma: Istituto per L’Oriente.

Harmanşah, Ömür. 2007. "Upright stones and building narratives: formation of a shared architectural practice in the Ancient Near East." In Ancient Near Eastern Art in Context. Studies in Honor of Irene J. Winter by her students, ed. J. Cheng e M. H. Feldman, 69-99. Leiden / Boston: Brill.

Liverani, Mario. 2009. “The King in the Palace.” Orientalia 78 (1):81-91.

__ 1988. Vicino Oriente Antico: Storia, Società, Economia. Roma: Laterza.

— 1979. “The Ideology of the Assyrian Empire." In Power and Propaganda. A Symposium on Ancient Empires, ed. M. T. Larsen, 297-317. Kobenhavn: Akademisk Forlag.

Luckenbill, D. D. 1968a. Ancient Records of Assyria and Babylonia. 2 vols. New York: Greenwood Press.

- 1968b. Ancient Records of Assyria and Babilonia. 2 vols. New York: Greenwood Press.

- 1924. The Annals of Sennacherib (Oriental Institute Publications 2). Chicago: University of Chicago Press.

Nadali, Davide. 2001-2003. "Guerra e morte: l'annullamento del nemico nella condizione del vinto." Scienze dell'Antichità 11:51-70.

Oded, Bustenay. War, Peace and Empire. Justifications for War in Assyrian Royal Inscriptions. Wiesbaden: Ludwig Reichert Verlag.

- 1979. Mass Deportations and Deportees in the Neo-Assyrian Empire. Wiesbaden: Ludwig Reichert Verlag.

Olmstead, A. T. 1918. “The Calculated Frightfulness of Ashur-nasir-apal." Journal of the American Oriental Society 38:209-63.

Piepkorn, A. C. 1933. Historical Prism Inscriptions of Ashurbanipal. I - Editions E, B1-5, D and K. Chicago: University of Chicago Press.

Reade, Julian. 2012. "Visual Evidence for the Status and Activities of Assyrian Scribes." Leggo! Studies Presented to Frederick Mario Fales on the Occasion of His 65th Birthday (Leipziger Altorientalische Studien 2), ed. G. B. Lanfranchi, D. Morandi Bonacossi, C. Pappi e S. Ponchia, 699-717. Wiesbaden: Harrassowitz.

—. (1998) 2007. Assyrian Sculpture. Reimpressão, London: The British Museum Press.

- 1979. "Ideology and Propaganda in Assyrian Art." In Power and Propaganda. A Symposium on Ancient Empires, ed. M. T. Larsen, 329-43. Copenhaga: Akademisk Forlag.

Reed, Stephanie. 2007. “'Blurring the Edges': A Reconsideration of the Treatment of Enemies in Ashurbanipal's Reliefs." In Ancient Near Eastern Art in 
Context: Studies in Honor of Irene J. Winter by her Students, ed. J. Cheng e M. H. Feldman, 101-30. Leiden / Boston: Brill.

Grayson, A. K. 1991. Assyrian Rulers of the Early First Millennium BC I (1114-859 BC). Vol. 2 de The Royal Inscriptions of Mesopotamia, Assyrian Periods. Toronto / Buffalo / London: Toronto University Press.

Grayson, A. Kirk e Jamie Novotny, eds. 2012. The Royal Inscriptions of Sennacherib, King of Assyria (704-681 BC), Part 1 (The Royal Inscriptions of the Neo-Assyrian Period 3/1). Winona Lake: Eisenbrauns.

Russell, John Malcolm. 1999. The Writing on the Wall. Studies in the Architectural Context of Late Assyrian Palace Inscriptions. Winona Lake: Eisenbrauns.

- 1991. Sennacherib's Palace Without Rival at Nineveh. Chicago: The Chicago University Press.

Starr, I., ed. 1990. Queries to the Sungod. Divination and Politics in Sargonid Assyria (State Archives of Assyria IV). Helsinki: Helsinki University Press.

Parpola, S., ed. 1997. Assyrian Prophecies (State Archives of Assyria IX). Helsinki: Helsinki University Press.

Fales, F. M. e J. N. Postgate, eds. 1995. Imperial Administrative Records, Part II: Provincial and Military Administration (State Archives of Assyria XI). Helsinki: Helsinki University Press.

Saggs, H. W. F. 1963. “Assyrian Warfare in the Sargonid Period.” Iraq 25:145-54.

Tadmor, Hayim. 1997. "Propaganda, Literature, Historiography: Cracking the Code of the Assyrian Royal Inscriptions." In Assyria 1995: Proceedings of the 10th Anniversary Symposium of the Neo-Assyrian Text Corpus Project, Helsinki, September 7-11, 1995, ed. S. Parpola e R. M. Whiting, 325-36. Helsinki: The Neo-Assyrian Text Corpus Project.

Thureau-Dangin, François. 1912. Une relation de la huitième campagne de Sargon II. Paris: Geuthner.

Watanabe, C. W. 2004. "The 'Continuous Style' in the narrative schemes of Ashurbanipal's reliefs.” Iraq 66:103-14.

Winter, Irene J. [1982] 2010. "Art as Evidence for Interaction: Relations between the Neo-Assyrian Empire and North Syria as Seen from the Monuments." In On Art in the Ancient Near East. Vol. 1, Of the First Millennium BCE, 525-62. Leiden: Brill.

Wiseman, Donald J. 1953. “Assyrian writing-boards.” Iraq 17:3-13. 


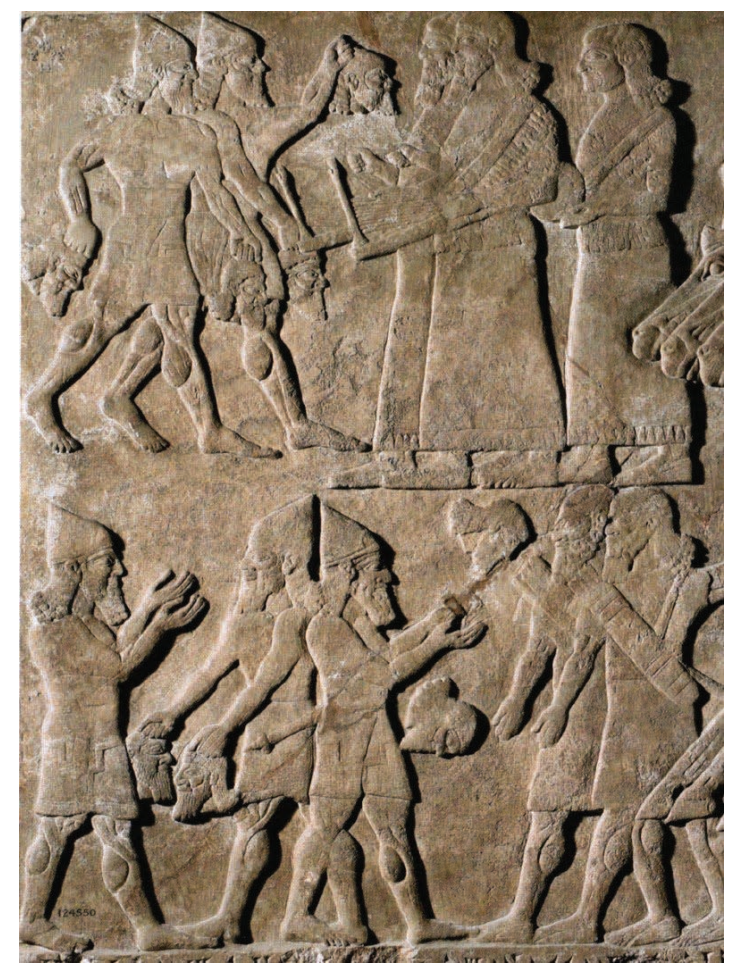

Fig. 1: Palácio de Aššurnasirpal, Kalhu (Nimrud). British Museum, ME 124550. (c) The Trustees of the British $\mathrm{Mu}$ seum.

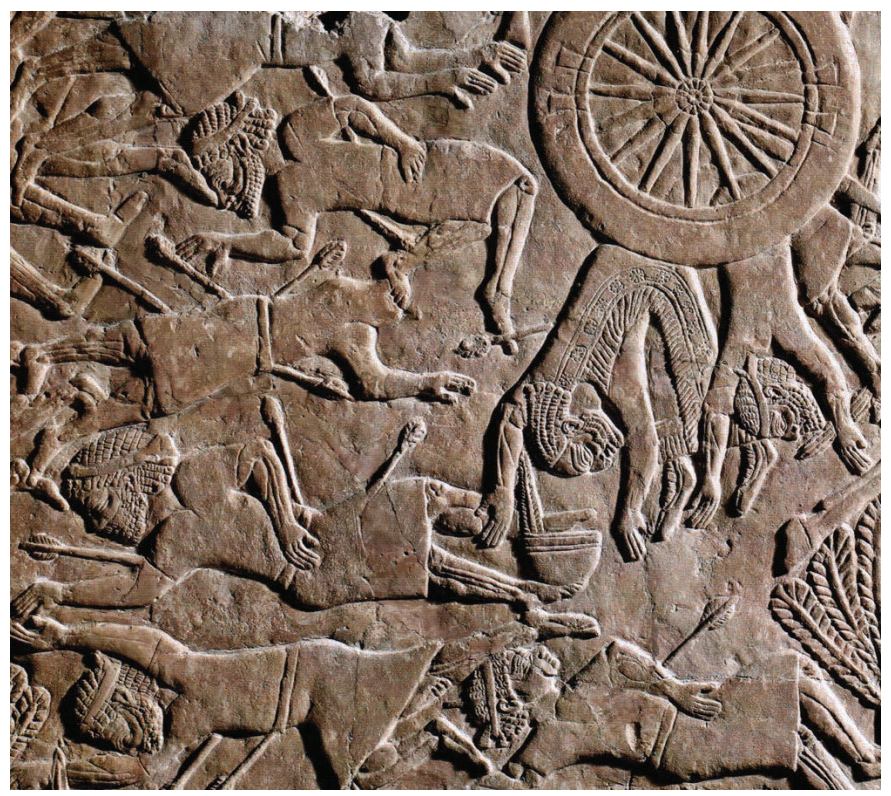

Fig. 2: Batalha de Til Tuba (detalhe). Assurbanípal, Palácio Sudoeste de Nínive. British Museum, ME 124801b. (C) The Trustees of the British Museum. 
Fig. 3: Teumman sendo decapitado por um soldado assírio. Palácio Sudoeste de Nínive. British Museum, ME 124801c. (C) The Trustees of the British Museum.
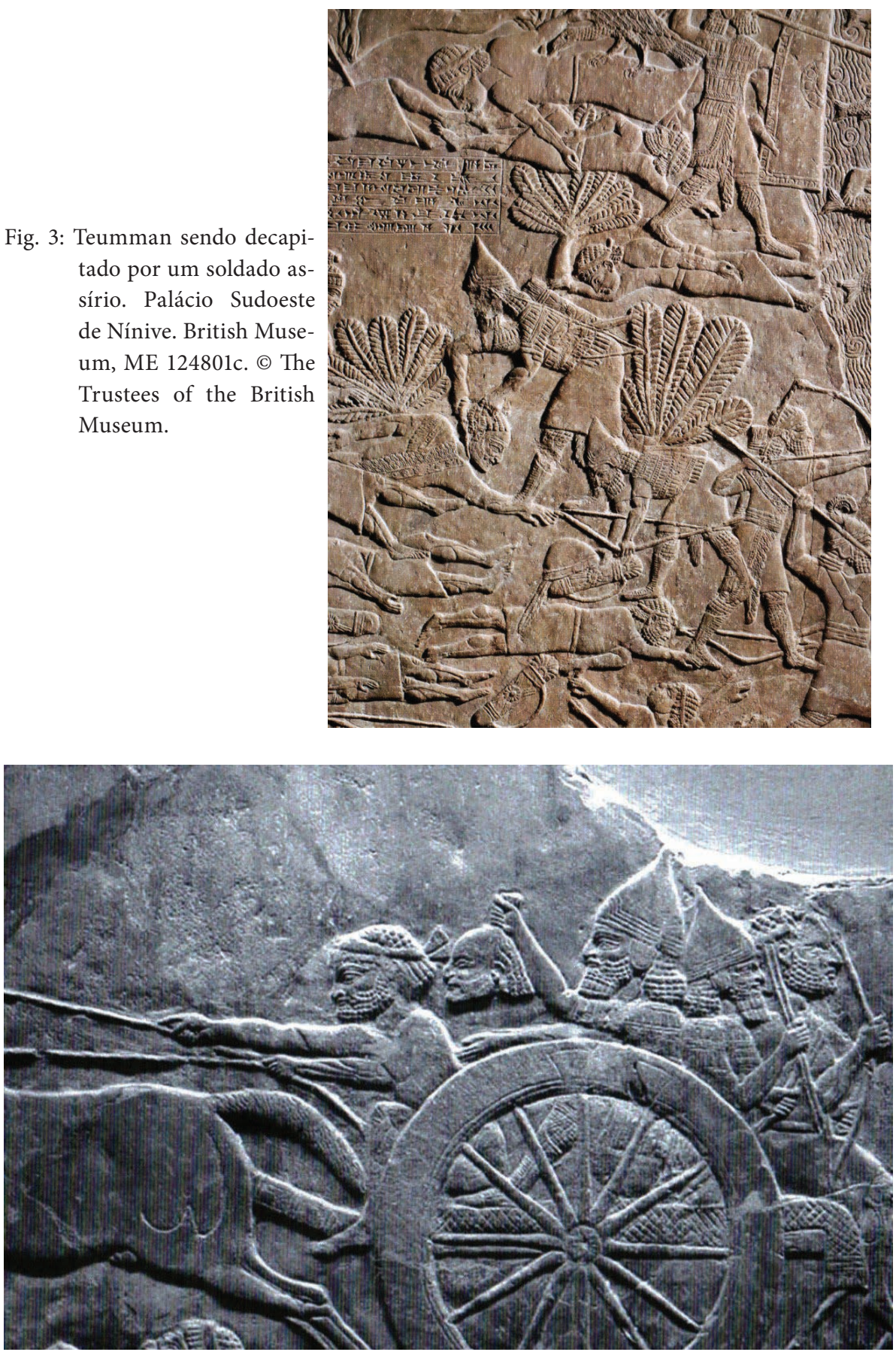

Fig. 4: A cabeça de Teumman sendo despachada para junto do rei assírio. British Museum, ME 124801a. (C) The Trustees of the British Museum. 


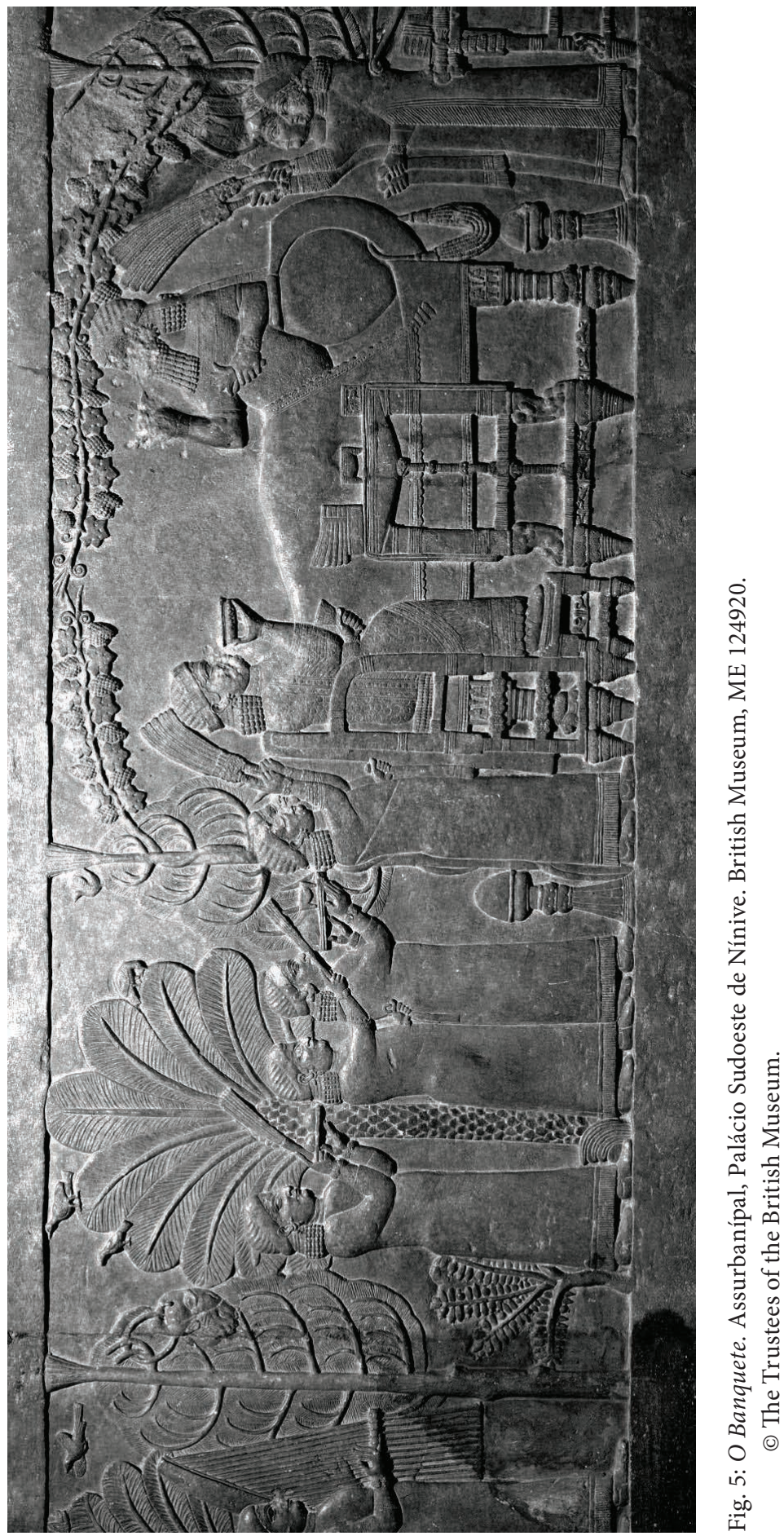




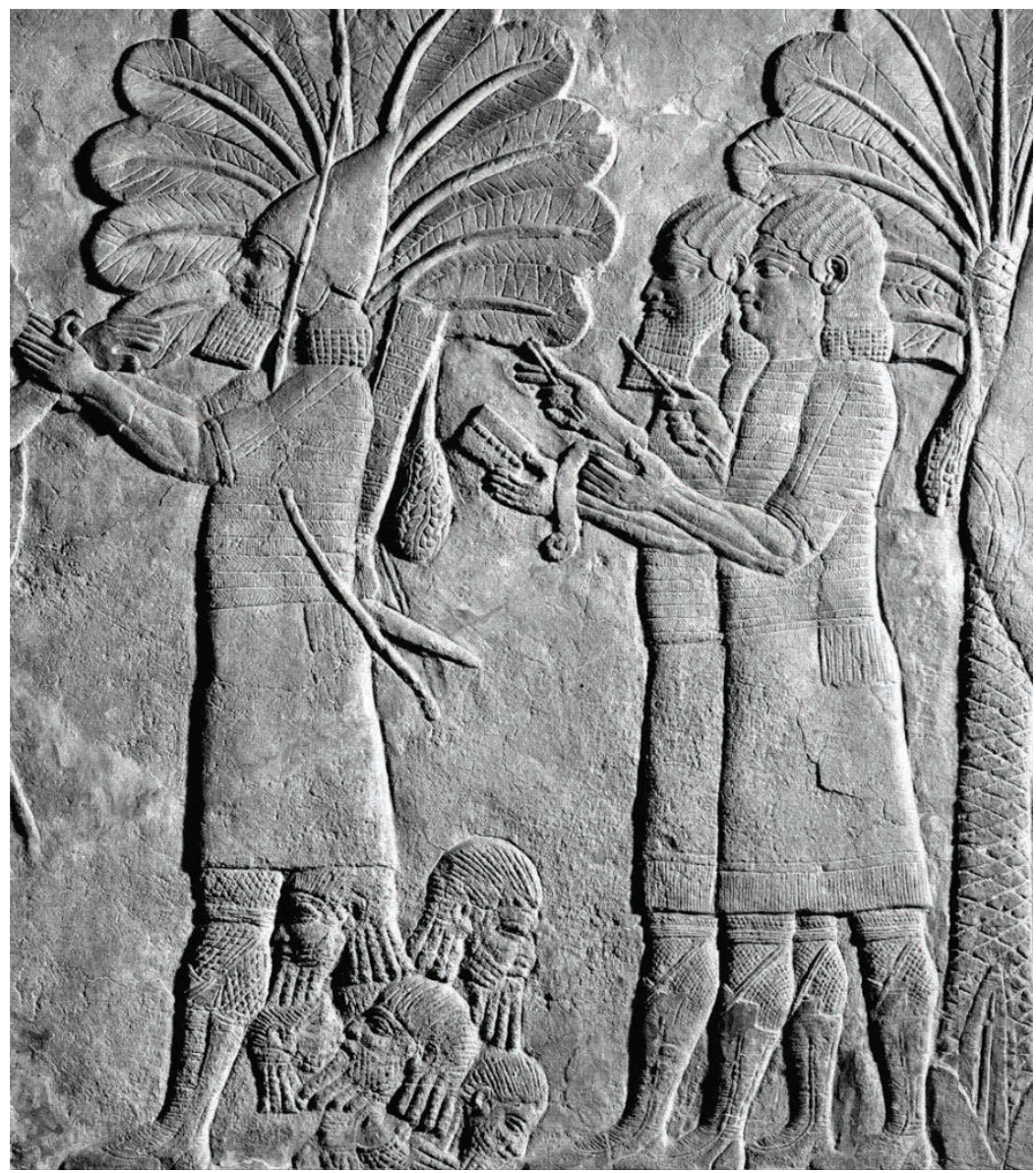

Fig. 6: Palácio Sudoeste de Nínive. British Museum, ME 124955-7. ( ) The Trustees of the British Museum.

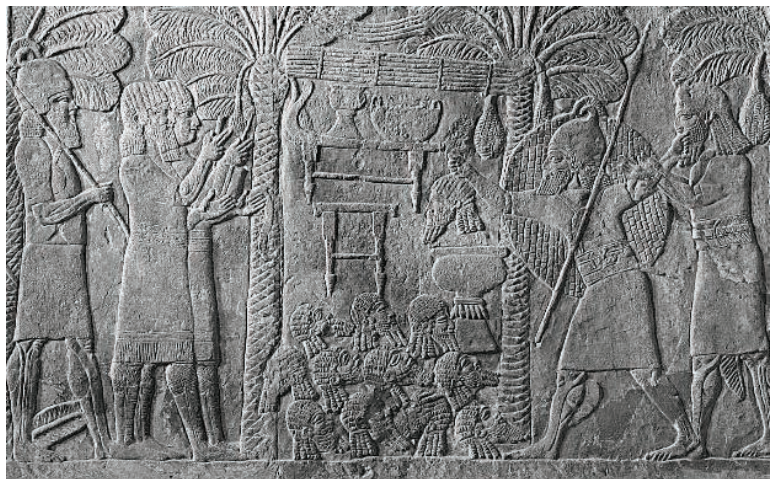

Fig. 7: Escribas contando cabeças e tributos. Palácio Sudoeste de Nínive. British Museum, ME 124825. (C) The Trustees of the British Museum. 